\title{
POTENSI KAYU RAKYAT DAN STRATEGI PENGEMBANGANNYA (STUDI \\ KASUS) DI HUTAN RAKYAT DESA BUANA SAKTI KECAMATAN \\ BATANGHARI KABUPATEN LAMPUNG TIMUR
}

\section{(THE POTENTIAL AND DEVELOPMENT STRATEGY OF TIMBER FROM \\ PRIVATE FORESTCASE STUDY IN FOREST OF BUANA SAKTI VILLAGE SUB DISTRICT OF BATANGHARI DISTRICT OF LAMPUNG TIMUR)}

\author{
Tri Putri Siadari, Rudi Hilmanto, dam Wahyu Hidayat \\ Jurusan Kehutanan Fakultas Pertanian Universitas Lampung \\ Jl. Pof. Dr. Sumantri Brojonegoro No. 1 Bandar Lampung 35145 \\ E-mail : Triputri.siadari@yahoo.com
}

\begin{abstract}
ABSTRAK
Penelitian ini bertujuan untuk mengetahui potensi kayu dari hutan rakyat dan menganalisis potensi pengembangan hutan rakyat di Desa Buana Sakti. Penelitian dilakukan pada bulan Maret-Mei 2012. Data yang dikumpulkan berupa data potensi kayu dari hutan rakyat yang dianalisis secara kuantitatif. Data pohon dan potensi kayunya diambil secara purposive dengan menggunakan petak ukur persegi berukuran $20 \mathrm{mx} 20 \mathrm{~m}$ serta menggunakan intensitas sampling sebesar 1\%. Analisis SWOT dilakukan untuk menentukan pengembangan yang tepat di hutan rakyat Desa Buana Sakti. Hasil penelitian menunjukkan potensi kayu di hutan rakyat Desa Buana Sakti secara keseluruhan yaitu sebesar $111,79 \mathrm{~m}^{3} / \mathrm{ha}$ dengan jenis kayu yaitu jati, karet, randu, jengkol, sengon, sonokeling, akasia, waru, cengkeh, melinjo dan jambu dengan potensi penerimaan kayu sebesar Rp.159.959.000/ha. Hasil perhitungan menunjukkan bahwa nilai INP jenis tanaman yang paling dominan adalah akasia yaitu sebesar $88,18 \%$ dengan total KR 51,88\%, FR 28,95\%, DR 7,35\%. Strategi pengembangan hutan rakyat yang dapat diterapkan adalah dengan memanfaatkan kekuatan yaitu melakukan pemeliharaan teratur, mengurangi kelemahan dengan meningkatkan pengetahuan akan hutan, menggunakan peluang dengan meningkatkan kesuburan tanaman, dan menjauhi ancaman dengan menggunakan teknologi yang sederhana.
\end{abstract}

Kata kunci : hasil hutan, kayu hutan rakyat, strategi pengembangan

\section{ABSTRACT}

This study aims to determine the potential of timber from private forest and to analyze the strategy to develop the management of private forest in Buana Sakti. This research held at March-May 2012. Tree data and timber potency were collected by using measurement plot of $20 \times 20 m$ with sampling intensity of $1 \%$. The datas were then analyzed quantitatively. SWOT analysis is performed to determine the proper development strategy of private forest in Buana Sakti. The results show that the potential of timber in private forest of Buana Sakti is 111,79 $\mathrm{m}^{3}$ which comprise of timber teak, rubber, randu, jengkol, sengon, sonokeling, acacia, waru, clove, melinjo with the potential revenue of Rp. 159.959.000/ha. The calculations show that the INP most dominant plant species are acacia that is equal to 88,18\% with 51,88\% of total $K R, F R 28,95 \%, 7,35 \%$ DR. The development strategy of private forest that needed to be applied are selecting the best quality and provide education to farmers about the important of forest.

Key words : forestry, strategy development, wood forest products 


\section{PENDAHULUAN}

Potensi hutan dicirikan keanekaragaman vegetasi karena merupakan sumberdaya paling dominan dari komponen hutan (Rijai, 2003). Kebutuhan kayu secara nasional diperkirakan mencapai 33,20 juta $\mathrm{m}^{3}$, sementara pasokan kayu dari hutan negara hanya mampu mencapai sekitar 8,05 juta $\mathrm{m}^{3}$ (BPS, 2008). Kesenjangan tersebut mendorong pemanfaatan sumberdaya hutan kearah eksploitasi yang berlebihan sehingga menyebabkan sumber daya hutan tersebut cenderung tidak mampu mengembalikan tingkat produktivitasnya. Salah satu alternatif dalam pemecahan masalah tersebut yakni dengan melakukan pembangunan hutan rakyat di luar kawasan hutan. Adanya hutan rakyat juga dapat memberikan peranan positif baik secara ekonomi maupun ekologi.

Kondisi hutan rakyat yang dimiliki oleh Desa Buana Sakti dapat dikatakan masih terjaga dan dapat dikembangkan. Oleh karena itu, perlu dilakukan penelitian untuk mengetahui potensi dari hutan rakyat Desa Buana Sakti, serta menganalisis strategi pengembangan hutan rakyat dan juga diharapkan dapat menjadi referensi bagi masyarakat untuk pembangunan hutan rakyat.

\section{METODE PENELITIAN}

Penelitian dilakukan di Desa Buana Sakti, Kecamatan Batanghari, Kabupaten Lampung Timur pada bulan Maret-Mei 2012. Objek yang diamati dalam penelitian ini adalah kawasan hutan rakyat, masyarakat, tokoh masyarakat, aparat desa dan instansi terkait di Desa Buana Sakti. Alat yang digunakan adalah kuisioner, alat hitung, alat tulis, tally sheet, tali raffia, christen hypsometer, pita ukur, kamera, dan komputer.

Jenis data yang dikumpulkan yaitu:

1. Data primer meliputi identitas responden, data hasil hutan kayu berupa jenis, volume dan harga kayu.

2. Data sekunder meliputi data yang diperoleh dari kondisi yang ada di lokasi penelitian seperti kondisi sosial ekonomi lokasi penelitian.

Metode pengumpulan data untuk data primer adalah pengamatan langsung di hutan rakyat dan metode wawancara bebas. Pengumpulan data sekunder menggunakan studi pustaka/literatur.

Sampel dalam penelitian berupa petak ukur. Jumlah petak ukur ditentukan dengan menggunakan rumus sebagai berikut (Safitri, 2009):

$\mathrm{n}=\frac{\text { Is } \mathrm{x} \mathrm{N}}{\text { LPC }}$

Keterangan:

$\mathrm{n} \quad=$ Jumlah petak ukur keseluruhan

$\mathrm{N}=$ Luas hutan rakyat (ha)

Is $\quad=$ Intensitas sampling

LPC = Luas petak contoh (ha)

Luas hutan rakyat di Desa Buana Sakti adalah 137,5 ha dan luas petak ukur yang digunakan dalam penelitian adalah 0,04 ha, sehingga jumlah petak ukur yang digunakan dalam penelitian adalah sebanyak 34 petak ukur.

Data hasil inventarisasi kayu di lahan hutan rakyat dihitung parameter-parameter tegakannya meliputi jenis pohon, jumlah pohon, luas bidang dasar (LBDS) dan volume per satuan luas. LBDS dapat dihitung menggunakan rumus sebagai berikut (Simon, 1999):

LBDS $=0,25 \times \pi \times \mathrm{Dbh}^{2}$

Perhitungan volume tegakan berdiri tanaman hutan rakyat dapat dihitung menggunakan rumus berikut : 


\section{$\mathrm{V}=\operatorname{LBDS} \times \mathrm{t} \times \mathrm{f}$}

Perhitungan potensi penerimaan dari hutan rakyat menggunakan rumus:

Potensi penerimaan $=\mathrm{V} \times$ Harga $\mathrm{kayu} / \mathrm{m}^{3}$

Indeks Nilai Penting (INP) menunjukkan kepentingan suatu jenis tumbuhan serta peranannya dalam komunitas. Pengolahan data indeks nilai penting (INP) meliputi (Indriyanto, 2006) :

1. Densitas (kerapatan)

Kerapatan (K)

$=\frac{\text { Jumlah individu suatu jenis }}{\text { Luas seluruh petak contoh }}$

Kerapatan Relatif (KR)

$=$ Kerapatan suatu jenis X $100 \%$

Kerapatan seluruh jenis

2. Frekuensi (F)

$=$ Jumlah petak ditemukannya suatu jenis

Jumlah seluruh petak

Frekuensi Relatif (FR)

$=$ Frekuensi suatu jenis X 100\%

Frekuensi seluruh jenis

3. Luas penutupan (D)

$=\quad$ LBDS suatu jenis

Luas seluruh petak contoh

4. Luas Penutupan Relatif (DR)

$$
=\frac{\text { Dominansi suatu jenis }}{\text { Dominan seluruh jenis }} \text { 100\% }
$$

5. Indeks Nilai Penting (INP)

$=\mathrm{KR}+\mathrm{FR}+\mathrm{DR}$

Analisis data berupa:

1. Analisis Deskriptif Kuantitatif

2. Analisis Deskriptif Kualitatif

3. Analisis SWOT ( Strength, Weakness, Opportunity, Threats) meliputi tiga tahapan yaitu tahap pengumpulan data internal dan eksternal, tahap analisis data serta tahap pengambilan keputusan (Rangkuti, 2006).

a. Matrik Faktor Internal (IFAS)

Penentuan komponen faktor strategi internal (IFAS) yaitu: hasil hutan kayu (produksi kayu), pengelolaan, sumber daya manusia, tenaga kerja dan pemasaran hasil kayu. Memberi bobot pada masing-masing skala mulai dari 100 (paling penting) sampai 0 (tidak penting), semua bobot tersebut harus berjumlah $100 \%$ yang akan menjadi bobot bagi masing-masing faktor.

b. Matriks Faktor Eksternal (EFAS)

Penentuan komponen faktor ekstenal (EFAS) yaitu: ekonomi, sosial dan budaya, teknologi, pemeliharaan tanaman, iklim dan cuaca, dan tabungan di masa depan. Faktor-faktor internal dan eksternal yaitu faktor kekuatan, kelemahan, ancaman dan peluang dimasukkan ke dalam matrik SWOT untuk dianalisis. Analisis SWOT ini menggambarkan secara jelas peluang dan ancaman eksternal yang dihadapi oleh petani hutan rakyat dan lahan hutan rakyat yang kemudian disesuaikan dengan kekuatan dan kelemahan yang dimiliki.

Matrik ini akan menghasilkan 4 kemungkinan strategi antara lain strategi SO, strategi ST, strategi WO, dan strategi WT. Silangkan masing-masing faktor sehingga didapat strategi SO, ST, WO, dan strategi WT. Pilihlah strategi yang sesuai dengan kuadran I, II, III, IV. 


\section{HASIL DAN PEMBAHASAN}

Petani hutan rakyat di Desa Buana Sakti pada umumnya menanam jenis pohon yang memiliki nilai ekonomi tinggi. Berdasarkan hasil penelitian terdapat 11 jenis pohon yang menjadi tanaman petani hutan rakyat di Desa Buana Sakti yaitu Sengon, Jengkol, Cengkeh, Sonokeling, Waru, Akasia, Randu, Karet, Tangkil, Jati dan Jambu, sebagaimana disajikan pada Tabel 1. Hasil perhitungan indeks nilai penting (INP) disajikan pada Tabel 2. INP merupakan metode yang digunakan untuk mengetahui jenis vegetasi yang dominan di hutan rakyat Desa Buana Sakti.

Tabel 1. Jenis-jenis pohon penghasil kayu di Desa Buana Sakti.

\begin{tabular}{lllrc}
\hline No & Nama Lokal & \multicolumn{1}{c}{ Nama Ilmiah } & Jumlah & Penggunaan \\
\hline 1. & Akasia & Acacia mangaium & 262 & Konstruksi \\
2. & Jati & Tectona grandis & 90 & Pertukangan \\
3. & Karet & Hevea brasiliensis & 74 & Konstruksi \\
4. & Randu & Ceiba pentandra & 30 & Konstruksi \\
5. & Sonokeling & Dalbergia latifolia & 21 & Pertukangan \\
6. & Sengon & Paraserianthes falcataria & 12 & Konstruksi \\
7. & Waru & Hibiscus tiliaceus & 8 & Pertukangan \\
8. & Jengkol & Pithecellobium lobatum & 3 & Konstruksi \\
9. & Cengkeh & Eugenia aromatica & 2 & Pertukangan \\
10. & Melinjo & Gnetum gnemon & 1 & Konstruksi \\
11. & Jambu & Psidium guajava & 1 & Kayu bakar \\
\hline
\end{tabular}

Sumber: Analisis data primer, 2012

Tabel 2. Hasil perhitungan jenis pohon.

\begin{tabular}{llrrrr}
\hline No & Jenis & KR (\%) & FR (\%) & DR (\%) & INP (\%) \\
\hline 1 & Akasia & 51,88 & 28,95 & 7,35 & 88,18 \\
2 & Jati & 17,82 & 21,05 & 5,35 & 44,22 \\
3 & Randu & 5,94 & 7,89 & 56,13 & 77,86 \\
4 & Karet & 14,65 & 15,79 & 2,10 & 24,65 \\
5 & Sonokeling & 4,16 & 2,63 & 8,90 & 15,69 \\
6 & Sengon & 2,57 & 10,53 & 11,26 & 24,36 \\
7 & Waru & 1,58 & 6,58 & 5,45 & 13,61 \\
8 & Jengkol & 0,59 & 2,63 & 2,00 & 5,22 \\
9 & Cengkeh & 0,40 & 1,32 & 0,73 & 2,44 \\
10 & Melinjo & 0,20 & 1,32 & 0,36 & 1,88 \\
11 & Jambu & 0,20 & 1,32 & 0,36 & 1,88 \\
\hline & Total & $\mathbf{1 0 0}$ & $\mathbf{1 0 0}$ & $\mathbf{1 0 0}$ & $\mathbf{3 0 0}$ \\
\hline
\end{tabular}

Sumber: Analisis data primer, 2012

Hasil perhitungan menunjukkan bahwa nilai INP tertinggi adalah jenis pohon Akasia $(88,18 \%)$. Menurut hasil wawancara jenis ini banyak ditanam oleh para petani karena Akasia merupakan jenis pohon yang cepat tumbuh dan juga didukung oleh struktur tanah di lahan hutan rakyat. Hal ini didukung oleh penelitian yang dilakukan Lestari (2012) yang menyebutkan bahwa tanaman Akasia merupakan tanaman yang mampu tumbuh di lahan berbatu karena memiliki perakaran yang dalam. INP tertinggi selanjutnya adalah jenis pohon Jati $(44,22 \%)$. Jati cukup banyak ditanam oleh petani hutan rakyat di Desa Buana Sakti karena memiliki nilai ekonomi tinggi (Tabel 2). 
Nilai INP yang tertinggi menunjukkan bahwa jenis tersebut mampu merebut zat hara, sinar matahari dan ruang tumbuh lebih banyak dari jenis lain, sehingga mempengaruhi pertumbuhan dan diameter pohon. Berdasarkan hasil penelitian, ditemukan jika suatu jenis tanaman tinggi, potensi penerimaan juga tinggi. Hal ini dikarenakan pengaruh jumlah tanaman yang lebih komersil lebih tinggi sehingga memperbesar nilai INP dan potensi penerimaan.

Volume pohon juga mempengaruhi potensi penerimaan di hutan rakyat Desa Buana Sakti. Semakin besar volume jenis pohon maka jenis tersebut memiliki potensi penerimaan lebih banyak atau memiliki nilai ekonomi lebih tinggi. Jenis pohon dengan nilai ekonomi tinggi akan dijaga keberadaannya oleh masyarakat karena berpotensi besar untuk meningkatkan pendapatan. Potensi penerimaan hasil hutan kayu di lahan hutan rakyat Desa Buana Sakti disajikan pada Tabel 3.

Tabel 3. Potensi Penerimaan Hasil Hutan Kayu di lahan Hutan Rakyat Desa Buana Sakti.

\begin{tabular}{|c|c|c|c|c|}
\hline No & Nama Lokal & $\begin{array}{c}\text { Harga rata-rata*// } \mathbf{m}^{3} \\
\left(\mathrm{Rp} / \mathrm{m}^{3}\right)\end{array}$ & $\begin{array}{c}\text { Volume rata-rata } \\
\left(\mathrm{m}^{3} / \mathrm{ha}\right)\end{array}$ & $\begin{array}{c}\text { Penerimaan } \\
(\mathrm{Rp} / \mathrm{Ha})\end{array}$ \\
\hline 1. & Jati & 2.000 .000 & 30,75 & 61.500 .000 \\
\hline 2. & Akasia & 1.500 .000 & 27,98 & 41.970 .000 \\
\hline 3. & Randu & 800.000 & 25,98 & 20.784 .000 \\
\hline 4. & Sengon & 1.700 .000 & 8,55 & 14.535 .000 \\
\hline 5. & Karet & 900.000 & 10,03 & 9.027 .000 \\
\hline 6. & Sonokeling & 1.500 .000 & 4,48 & 6.720 .000 \\
\hline 7. & Waru & 1.700 .000 & 2,34 & 3.978 .000 \\
\hline 8. & Jengkol & 900.000 & 1,10 & 990.000 \\
\hline 9. & Cengkeh & 1.000 .000 & 0,35 & 350.000 \\
\hline 10. & Melinjo & 600.000 & 0,12 & 72.000 \\
\hline 11. & Jambu & 300.000 & 0,11 & 33,000 \\
\hline & & Jumlah & 111,79 & 159.959 .000 \\
\hline
\end{tabular}

Sumber : Analisis data primer, 2012

Berdasarkan Tabel 3, dapat dilihat total potensi penerimaan hasil hutan kayu di hutan rakyat Desa Buana Sakti yaitu sebesar Rp.159.959.000/ha dengan total volume yaitu $111,79 \mathrm{~m}^{3} / \mathrm{ha}$ lebih rendah dibandingkan dengan penelitian Sukadaryati (2006) yang menghasilkan potensi hutan rakyat di Indonesia sebesar Rp. 262.929.193 /ha dengan komposisi jenis Jati, Sengon, Mahoni, Bambu, Akasia, Pinus dan Sonokeling. Harga ini diasumsikan berdasarkan volume kayu per jenis dan data volume pohon yang telah diambil pada saat penelitian.

Teknik pengelolaan yang dilakukan masyarakat di hutan rakyat Desa Buana Sakti masih menggunakan teknik silvikultur yang sederhana. Sebelum melakukan penanaman, petani melakukan penyiapan lahan dengan cara membabat semak belukar yang ada disekitar lahan, kemudian tanah dicangkul untuk dijadikan sebagai lubang tanam. Kegiatan pembabatan semak belukar dan pembuatan lubang tanam biasanya dilakukan masyarakat pada akhir musim kemarau, setelah memasuki musim penghujan barulah bibit ditanam pada lubang tanam yang telah disediakan.

Kegiatan pemeliharaan yang dilakukan juga masih sederhana, masyarakat beranggapan bahwa tanaman kehutanan masih dapat tumbuh walaupun tanpa ada kegiatan penyiangan dan pemupukan. Misalnya pada tanaman Sengon, kegiatan pemeliharaan dilakukan hingga umur 3 tahun dan Jati hingga umur 8 tahun. Pada umur tanaman tersebut biasanya semak belukar dan gulma tidak dapat tumbuh karena ternaungi oleh tajuk tanaman yang telah besar.

Sistem pemanenan yang dilakukan petani hutan rakyat yaitu sistem tebang pilih, yakni memilih pohon yang mempunyai ukuran diameter lebih besar untuk ditebang terlebih dahulu. 
Kegiatan pengelolaan ini sejalan dengan penelitian yang dilakukan Rachmadani (2011) di hutan rakyat Jati di Kabupaten Jepara yang menjelaskan petani hutan rakyat di kabupaten Jepara melakukan pengelolaan dengan melakukan teknik silvikultur yang masih sederhana.

Pada penelitian ini, analisis SWOT digunakan untuk menganalisis potensi pengembangan hutan rakyat di Desa Buana Sakti. Analisis ini digunakan untuk memanfaatkan potensi yang dimiliki hutan rakyat guna memperoleh dan meningkatkan keuntungan dari kawasan hutan rakyat tersebut.

Kerangka matrik faktor strategi internal untuk kekuatan (strength) yang dimiliki oleh hutan rakyat dapat dilihat pada Tabel 4.

Tabel 4. Kerangka matrik faktor strategi internal untuk kekuatan (strength).

\begin{tabular}{|c|c|c|c|c|c|}
\hline $\begin{array}{l}\text { Komponen } \\
\text { (1) }\end{array}$ & $\begin{array}{l}\text { Kekuatan } \\
\text { (2) }\end{array}$ & $\begin{array}{l}\text { Bobot } \\
\text { (3) }\end{array}$ & $\begin{array}{r}\text { Rating } \\
\text { Skor }\end{array}$ & $\begin{array}{l}\text { Total } \\
(5)\end{array}$ & $\begin{array}{l}\text { Rangking } \\
\text { (6) }\end{array}$ \\
\hline Produksi & $\begin{array}{l}\text { kayu yang dihasilkan } \\
\text { berkualitas }\end{array}$ & 0,25 & 4 & 1 & 1 \\
\hline Pengelolaan & $\begin{array}{l}\text { dilakukan pengelolaan } \\
\text { alami }\end{array}$ & 0,25 & 4 & 1 & 2 \\
\hline SDM & $\begin{array}{l}\text { sebagian petani sudah } \\
\text { berpengalaman }\end{array}$ & 0,20 & 3 & 0,6 & 4 \\
\hline Tenaga kerja & $\begin{array}{l}\text { tenaga kerja yang } \\
\text { diperlukan sedikit }\end{array}$ & 0,20 & 4 & 0,8 & 3 \\
\hline Pemasaran kayu & $\begin{array}{l}\text { dekat dengan penjualan } \\
\text { kayu. }\end{array}$ & 0,10 & 2 & 0,2 & 5 \\
\hline Total & & & & 3,6 & \\
\hline
\end{tabular}

Sumber: Analisis data primer, 2012

Salah satu kekuatan yang dimiliki oleh hutan rakyat yaitu hasil kayu yang berkualitas dan pengelolaan yang menggunakan silvikultur sederhana sehingga tidak mengeluarkan banyak biaya.

Salah satu kelemahan yang dimilki oleh hutan rakyat Desa Buana Sakti adalah kurangnya jaringan pemasaran kayu, sehingga harga kayu yang ada pada tingkat petani cenderung murah karena harga jual kayu kerap ditentukan oleh para pembeli (tengkulak), sehingga dalam hal ini petani kerap berada pada posisi lemah dalam menetapkan harga jual kayu terutama ketika petani menjual kayu dalam keadaan terdesak. Kerangka matrik kelemahan dapat dilihat pada Tabel 5.

Tabel 5. Kerangka matrik faktor strategi internal untuk kelemahan (weakness).

\begin{tabular}{|c|c|c|c|c|c|}
\hline $\begin{array}{l}\text { Komponen } \\
\quad(1)\end{array}$ & $\begin{array}{l}\text { Kelemahan } \\
\text { (2) }\end{array}$ & $\begin{array}{c}\text { Bobot } \\
(3)\end{array}$ & $\begin{array}{c}\text { Rating } \\
\text { (4) }\end{array}$ & $\begin{array}{r}\text { Total } \\
\text { skor }\end{array}$ & $\begin{array}{l}\text { Rangking } \\
(5)\end{array}$ \\
\hline \multirow[t]{2}{*}{ Produksi } & $\begin{array}{l}\text { harga jual kayu } \\
\text { cenderung murah }\end{array}$ & 0,30 & 4 & 1,2 & 1 \\
\hline & $\begin{array}{l}\text { keterbatasan alat } \\
\text { dalam pengelolaan }\end{array}$ & 0,25 & 3 & 0,75 & 2 \\
\hline SDM & $\begin{array}{l}\text { pengetahuan akan } \\
\text { fungsi hutan kurang }\end{array}$ & 0,10 & 2 & 0,20 & 5 \\
\hline Tenaga kerja & $\begin{array}{l}\text { pengetahuan tenaga } \\
\text { kerja kurang }\end{array}$ & 0,20 & 3 & 0,60 & 3 \\
\hline Pemasaran kayu & $\begin{array}{l}\text { jaringan penjualan } \\
\text { kayu kurang }\end{array}$ & 0,15 & 2 & 0,30 & 4 \\
\hline Total & & & & 3,05 & \\
\hline
\end{tabular}

Sumber: Analisis data primer, 2012 
Salah satu cara untuk mengatasi kelemahan yang ada yaitu dengan memperkuat peluang yang ada, dapat dilihat pada Tabel 6.

Tabel 6. Kerangka Matrik strategi eksternal untuk peluang (opportunities).

\begin{tabular}{|c|c|c|c|c|c|}
\hline $\begin{array}{l}\text { Komponen } \\
\text { (1) }\end{array}$ & $\begin{array}{l}\text { Peluang } \\
\text { (2) }\end{array}$ & $\begin{array}{c}\text { Bobot } \\
\text { (3) }\end{array}$ & $\begin{array}{c}\text { Rating } \\
\text { (4) }\end{array}$ & $\begin{array}{l}\text { Total } \\
\text { skor }\end{array}$ & $\begin{array}{c}\text { Rangking } \\
\text { (5) }\end{array}$ \\
\hline $\begin{array}{l}\text { Ekonomi, sosial, } \\
\text { Budaya }\end{array}$ & $\begin{array}{l}\text { pertumbuhan } \\
\text { dan kebutuhan } \\
\text { kayu meningkat }\end{array}$ & 0,20 & 4 & 0,80 & 2 \\
\hline Teknologi & $\begin{array}{l}\text { kerjasama } \\
\text { dalam pengadaan alat }\end{array}$ & 0,20 & 3 & 0,60 & 4 \\
\hline $\begin{array}{l}\text { Pemeliharaan } \\
\text { tanaman }\end{array}$ & $\begin{array}{l}\text { peningkatan } \\
\text { kesuburan } \\
\text { tanaman }\end{array}$ & 0,25 & 4 & 1,00 & 1 \\
\hline Iklim dan cuaca & $\begin{array}{l}\text { musim hujan } \\
\text { mempercepat } \\
\text { tanaman }\end{array}$ & 0,15 & 2 & 0,30 & 5 \\
\hline $\begin{array}{l}\text { Tabungan di masa } \\
\text { depan }\end{array}$ & $\begin{array}{l}\text { dapat dijadikan } \\
\text { uang saat dibutuhkan }\end{array}$ & 0,20 & 3 & 0,60 & 3 \\
\hline Total & & & & 3,30 & \\
\hline
\end{tabular}

Sumber: Analisis data primer, 2012

Kelembagaan yang ada dapat menjadi salah satu peluang untuk mengatasi kelemahan di hutan rakyat. Diharapkan dengan adanya kelembagaan yang kuat, para petani dapat mendapatkan masukan ataupun pengetahuan tentang hutan rakyat yang mereka kelola.

Ancaman yang ada dapat menjadi faktor penghambat pengembangan hutan rakyat di Desa Buana Sakti, salah satu diantaranya yaitu adanya serangan hama yang menggangggu pertumbuhan tanaman, berdasarkan hasil wawancara apabila salah satu pohon terkena serangan hama, maka pohon tersebut akan ditebang dan dimusnahkan agar hama tidak menjalar ke mana-mana. Tanaman yang terkena hama ini dapat menyebabkan kerugian ekonomi bagi para petani. Matrik faktor ancaman dapat dilihat pada Tabel 7.

Tabel 7. Kerangka matrik strategi eksternal untuk ancaman (threats).

\begin{tabular}{|c|c|c|c|c|c|}
\hline $\begin{array}{c}\text { Komponen } \\
\text { (1) }\end{array}$ & $\begin{array}{l}\text { Ancaman } \\
(2)\end{array}$ & $\begin{array}{c}\text { Bobot } \\
(3)\end{array}$ & $\begin{array}{c}\text { Rating } \\
(4)\end{array}$ & $\begin{array}{c}\text { Total } \\
\text { skor }\end{array}$ & $\begin{array}{c}\text { Rangking } \\
\text { (5) }\end{array}$ \\
\hline $\begin{array}{l}\text { Ekonomi,sosial, } \\
\text { dan budaya }\end{array}$ & $\begin{array}{l}\text { tingkat preferensi } \\
\text { masyarakat akan } \\
\text { fungsi hutan menurun }\end{array}$ & 0,20 & 4 & 0,40 & 4 \\
\hline Teknologi & $\begin{array}{l}\text { perkembangan teknologi } \\
\text { yang sulit diikuti }\end{array}$ & 0,20 & 3 & 0,60 & 2 \\
\hline $\begin{array}{l}\text { Pemeliharaan } \\
\text { tanaman }\end{array}$ & serangan hama & 0,25 & 4 & 1,00 & 1 \\
\hline Iklim dan cuaca & $\begin{array}{l}\text { musim kemarau } \\
\text { yang panjang }\end{array}$ & 0,15 & 2 & 0,30 & 5 \\
\hline $\begin{array}{l}\text { Tabungan masa } \\
\text { depan }\end{array}$ & lamanya pertumbuhan & 0,20 & 3 & 0,60 & 3 \\
\hline Total & & & & 2,90 & \\
\hline
\end{tabular}

Sumber: Analisis data primer, 2012 
Tabel 8. Pembobotan untuk diagram SWOT faktor internal dan eksternal.

\begin{tabular}{|c|c|c|c|c|}
\hline \multirow[t]{2}{*}{ Uraian } & \multicolumn{2}{|c|}{ Faktor Internal } & \multicolumn{2}{|c|}{ Faktor Eksternal } \\
\hline & Kekuatan & Kelemahan & Peluang & Ancaman \\
\hline$\overline{\text { Bobot } x \text { Rating }}$ & 3,6 & 3,05 & 3,30 & 2,90 \\
\hline Selisih & \multicolumn{2}{|r|}{$+0,55$} & \multicolumn{2}{|r|}{$+0,4$} \\
\hline
\end{tabular}

Sumber: Analisis data primer, 2012

Setelah dilakukan pembobotan untuk faktor internal dan eksternal, dihasilkan selisih dari faktor internal yaitu $+0,55$ sedangkan selisih dari faktor eksternal yaitu $+0,4$. Setelah diperoleh angka dari selisih faktor internal dan eksternal, maka dapat dibuat diagram SWOT, dapat dilihat pada Gambar 1.

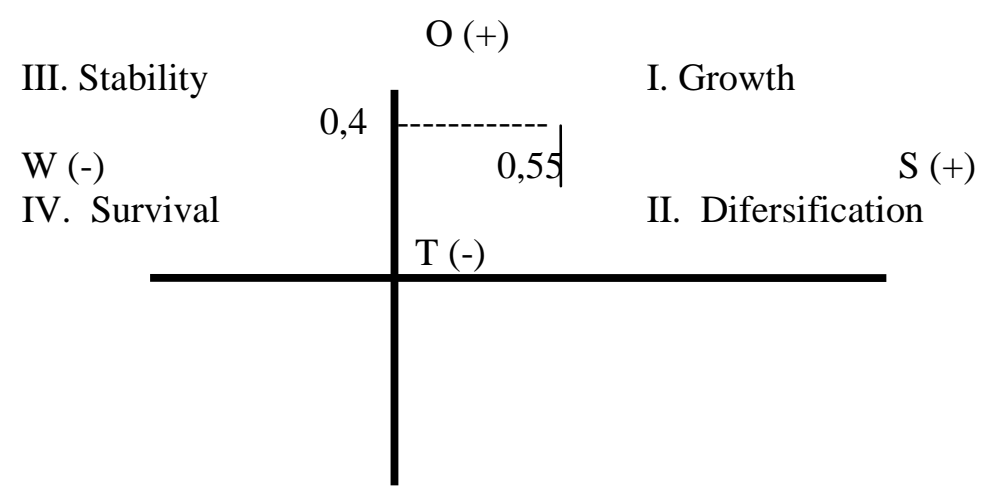

Gambar 1. Diagram SWOT strategi pengembangan hutan rakyat di Desa Buana Sakti Kecamatan Batanghari Kabupaten Lampung Timur.

Berdasarkan Gambar 1 dapat dilihat potensi perkembangan hutan rakyat berada pada kuadran 1, yaitu hutan rakyat berada dalam kondisi pertumbuhan, sehingga hutan rakyat Desa Buana Sakti dapat lebih dikembangkan. Analisis SWOT strategi pengembangan hutan rakyat di Desa Buana Sakti Kecamatan Batanghari Kabupaten Lampung Timur dapat dilihat pada Gambar 2. 


\begin{tabular}{|c|c|c|}
\hline Faktor Internal & $\begin{array}{l}\text { Strenghts (S) } \\
\text { Kayu yang dihasilkan berkualitas } \\
\text { Mudah dalam pengelolaan } \\
\text { Sebagian petani sudah } \\
\text { berpengalaman } \\
\text { Tenaga kerja yang diperlukan sedikit. } \\
\text { Dekat dengan saluran pemasaran } \\
\text { kayu }\end{array}$ & $\begin{array}{l}\text { Weakness (W) } \\
\text { Harga jual kayu cenderung murah } \\
\text { Terbatasnya alat dalam pengelolaan } \\
\text { Pengetahuan akan fungsi hutan } \\
\text { kurang. } \\
\text { Pengetahuan tenaga kerja kurang } \\
\text { Jaringan pemasaran kayu lemah }\end{array}$ \\
\hline $\begin{array}{l}\text { Opportunities (O) } \\
\text { Pertumbuhan dan kebutuhan } \\
\text { kayu meningkat. } \\
\text { Kerjasama dalam pengadaan } \\
\text { alat. } \\
\text { Peningkatan kesuburan } \\
\text { tanaman. } \\
\text { Musim hujan mempercepat } \\
\text { pertumbuhan tanaman. } \\
\text { Dapat dijadikan uang saat } \\
\text { dibutuhkan }\end{array}$ & $\begin{array}{l}\text { Strategi (SO) } \\
\text { Dengan peningkatan pertumbuhan } \\
\text { kayu, maka kayu yang dihasilkan } \\
\text { akan semakin berkualitas. } \\
\text { Dengan adanya kerjasama dalam } \\
\text { pengadaan alat, akan mempermudah } \\
\text { pengelolaan hutan rakyat. } \\
\text { Petani yang berpengalaman akan } \\
\text { semakin mengetahui cara } \\
\text { peningkatan kesuburan tanaman. } \\
\text { Tenaga kerja yang sedikit namun } \\
\text { memanfaatkan musim hujan akan } \\
\text { mendorong masyarakat untuk } \\
\text { mengembangkan hutan rakyat. } \\
\text { Pemasaran kayu yang mudah } \\
\text { dijangkau akan mempercepat } \\
\text { penjualan kayu. }\end{array}$ & $\begin{array}{l}\text { Strategi WO } \\
\text { Harga jual kayu yang cenderung } \\
\text { murah dapat diatasi dengan } \\
\text { meningkatkan pertumbuhan kayu. } \\
\text { Mengadakan kerjasama dalam } \\
\text { pengadaan alat untuk mengatasi } \\
\text { keterbatasan alat. } \\
\text { Adanya penyuluhan akan } \\
\text { membantu masyarakat dalam } \\
\text { menambah pemahaman tentang } \\
\text { pemeliharaan tanaman. } \\
\text { Musim hujan akan membantu } \\
\text { pertumbuhan tanaman. }\end{array}$ \\
\hline $\begin{array}{l}\text { Threats (T) } \\
\text { Tingkat preferensi masyarakat } \\
\text { akan fungsi hutan menurun. } \\
\text { Perkembangan teknologi yang } \\
\text { sulit diikuti karena } \\
\text { memerlukan biaya yang } \\
\text { tinggi. } \\
\text { Serangan hama. } \\
\text { Musim kemarau yang panjang. } \\
\text { Lamanya pertumbuhan. }\end{array}$ & $\begin{array}{l}\text { Strategi (ST) } \\
\text { Hasil kayu yang berkualitas baik } \\
\text { akan menjadi panduan masyarakat } \\
\text { dalam pemeliharaan tanaman. } \\
\text { Melakukan pengelolaan yang } \\
\text { sederhana sehingga tidak perlu } \\
\text { menggunakan teknologi yang rumit. } \\
\text { Pengalaman petani dalam mengelola } \\
\text { hutan rakyat dapat membantu dalam } \\
\text { membasmi hama. }\end{array}$ & $\begin{array}{l}\text { Strategi (WT) } \\
\text { Meningkatkan pengetahuan } \\
\text { masyarakat akan fungsi hutan. } \\
\text { Menggunakan teknologi dan } \\
\text { pemeliharaan yang alami. } \\
\text { Melakukan penyimpanan air } \\
\text { sebelum musim kemarau panjang. }\end{array}$ \\
\hline
\end{tabular}

Gambar 2. Matrik SWOT Analisis strategi pengembangan di hutan rakyat Desa Buana Sakti.

\section{SIMPULAN}

Potensi kayu di hutan rakyat desa Buana Sakti adalah sebesar $111,79 \mathrm{~m}^{3} /$ ha yang terdiri atas kayu Jati, Karet, Sengon, Sonokeling, Akasia, Cengkeh, Waru, Jengkol, Melinjo, Jambu dan Randu dengan potensi penerimaan sebesar Rp.159.959.000/ha.

Strategi pengembangan hutan rakyat di Desa Buana Sakti yang perlu diterapkan adalah dengan memanfaatkan faktor kekuatan yaitu dengan melakukan pemeliharaan teratur khususnya terhadap tanaman jenis akasia (Acacia mangium) yang memiliki pertumbuhan yang relatif cepat dengan potensi penerimaan yang cukup besar dan mengurangi faktor kelemahan yaitu meningkatkan pengetahuan akan hutan serta menjauhi ancaman dengan menggunakan teknologi yang sederhana yang dapat membantu petani hutan rakyat dan mengahadapi tantangan akan kebutuhan kayu yang semakin meningkat. 


\section{DAFTAR PUSTAKA}

Badan Pusat Statistik. 2008. Statistik Perusahaan Hak Pengusahaan Hutan. Buku. Jakarta: Badan Pusat Statistik.

Indriyanto. 2006. Ekologi Hutan. Buku. PT. Bumi Aksara. Jakarta.

Lestari, F. 2012. Perbanyakan tanaman akasia (Acacia sp) melalui teknik invitro di Balai Besar Penelitian Bioteknologi dan Pemuliaan Tanaman Hutan. Yogyakarta.

Profil Desa Buana Sakti. 2011. Badan Pemberdayaan Masyarakat Desa Kabupaten Lampung Timur. tidak dipublikasikan.

Rachmadani, M. C. 2011. Dinamika potensi tegakan dan sistem pengelolaan hutan rakyat jati di Kabupaten Jepara. Skripsi. Fakultas Kehutanan, Institut Pertanian Bogor.

Rangkuti, F. 2006. Analisis SWOT Teknik Membedah Kasus Bisnis. Buku. Gramedia Pustaka Utama. Jakarta.

Rijai, L. 2003. Bioprospeksi suatu paradigma baru dalam pengelolaan hutan berkelanjutan. Disertasi. Institut Pertanian Bogor.

Safitri, E. 2009. Identifikasi dan inventarisasi pengelolaan hutan rakyat di Kecamatan BiruBiru. Skripsi. Universitas Sumatera Utara.

Simon, H. 1999. Pengelolaan Hutan Bersama Rakyat. BIGRAF Publishing. Yogyakarta.

Sukadaryati. 2006. Potensi hutan rakyat di Indonesia dan permasalahannya. Skripsi. Fakultas Kehutanan. Institut Pertanian Bogor. 